\title{
Accessing Web Based Health Care and Resources for Mental Health: Interface Design Considerations for People Experiencing Mental Illness
}

\author{
Alice Good and Arunasalam Sambhanthan \\ School of Computing \\ University of Portsmouth \\ PO1 3AE, UK \\ alice.good@port.ac.uk
}

\begin{abstract}
A significant proportion of society experience mental illness, many of which uses the Web for advice and support relating to their illness. With a high proportion of society experiencing anxiety and depression, it is important that web designers are informed of specific requirements to ensure Websites are accessible, particularly those websites that provide support and advice for mental health. Anxiety and depression can affect cognitive functioning, which can then impact upon the accessibility of web based information. The premise of this research is to look at design elements that are most likely to cause issues for people experiencing anxiety and depression. During a focus group, people who have a diagnosis of anxiety and depression were asked to discuss difficulties they experienced when carrying out specific tasks. The results from the study show that the problems encountered can be categorized under three main themes: information retrieval; information presentation and the understanding of information.
\end{abstract}

Keywords: Web Accessibility, Guidelines, Health Care, Mental Illness, Anxiety, Depression.

\section{Introduction}

Across the world, a significant proportion of society experience mental illness, many of which will use the Internet. The World Health Organization states that more than 450 million people worldwide have a mental health problem. (WHO, 2010) To put the problem into perspective, both the USA and the UK report 1 in 4 people who have experienced mental illness (ONS, 2013; NIMH, 2012). Anxiety is one of the most common mental health disorders with 1 in 5 people affected (NIMH, 2012, particularly people between the ages of 40 and 59 or over 80 (ONS, 2013). When one considers the predominance of mental illness within society, particularly in terms of anxiety and depression, the issue of web accessibility for this user group should be an important consideration. To clarify, we use the term web accessibility to imply the ease with which people can access web based information, regardless of impairment 
or ability Thus, when designing web resources specifically for people with mental illness, web accessibility should be paramount.

\subsection{Using the Web as a Resource for Self-Help in Mental Health}

The Web is increasingly providing access to the provision of health care via the Web and plays a significant role in providing information on mental health. This includes a variety of resources that facilitate support and self-help, such as information sites; social networking sites; communities as well as others (Good et al, 2013; Van de belt et al., 2010). When we consider that in 2010, people in the USA spent 10 billion dollars on self-help materials (Harwood \& L'Abate, 2010); it is hardly surprising that a significant number of people are increasingly also looking to the Web for self-help resources. Easy access to information and anonymity as opposed to potential stigma from using more traditional routes has certainly helped to pave the way.

1 in 5 people with a diagnosed mental health condition will use the Web to find information about mental health (Powell et al, 2007). In fact Powell at al carried out a study in 2007 that sought to investigate the extent of information seeking on mental health. The study found that $18 \%$ of Internet users had searched for information on mental health, with a higher prevalence with people who had either a history of mental health problems or who were currently experiencing psychological problems. One of the recommendations from the study was that 'there needed to be a better understanding of how individuals actually use the Internet'. (Powell et al, 2007). Given the extent to which people clearly use the Internet as a tool to manage their illnesses, it is important to ensure that the information is accessible, particularly given the effect that anxiety and depression has upon cognitive functioning.

Whilst research into designing for sensory and physical impairments has led the way with accessibility related research, it is more recently however, that there has been a drive towards focusing upon designing for people with mental illnesses (Doherty et al, 2010; Rotondi et al, 2007). When looking at accessibility design guidelines, mental health disorders tend to be categorized under cognitive impairments. However, simply designing for cognitive impairments in general presents many challenges, not least because of the range of impairments included under the label of 'cognitive' and in turn, the complex diversity of user needs arising from this 'range.

\section{The Effect of Anxiety and Depression Upon Cognitive Functioning}

Anxiety and depression affects cognitive functioning in many ways but what is particularly interesting is that the same issues relate to both disorders. Anxiety and depression has been shown to affect cognitive functioning in activities that relate to: learning; memory; attention and verbal ability (Papazacharias \& Nardini 2012; Gualtieri \& Morgan 2008; Porter at Al, 2003). Furthermore, cognitive performance can be significantly decreased up to 3 years even before depression has been 
diagnosed and episodic memory impairment in particular can remain after recovery from depression (Airaksinen, $\mathrm{E}$ et $\mathrm{Al}, 2005$ ). There are also a number of neurobiological studies that indicate a correlation between depression and functional changes in brain regions that relate to cognitive functioning, particularly episodic memory (Campbell at al, 2004; Frodl et al, 2002

These problems in cognitive functioning will undoubtedly impact upon the ease with which people that are experiencing anxiety and/or depression, can perceive and understand Web based information and indeed operate certain interface components. Web pages can then become inaccessible to people who are experiencing impaired cognitive functioning as a result of anxiety and/or depression. The identified user group may well already be experiencing symptoms relating to a mental health disorder prior to commencing their information seeking activity. If they encounter accessibility issues relating to the design of web pages, this could result in increased anxiety which then further impacts upon cognitive functioning.

\section{Design Guidelines for Cognitive Impairments}

There continues to be a drive towards making the Web inclusive; to ensure that regardless of user needs, the Web can still be accessible to all. These needs can relate to physical, sensory and cognitive deficits; both permanent and indeed temporary. Published guidelines have been available since 1999 to advise on Web accessibility for a wide range of physical and cognitive impairments (Trace Research and Development Center, 1996; World Wide Web Consortium [W3C], 1999; W3C, 2004). Yet whilst accessibility guidelines have focused upon some cognitive impairments, there is less that relates specifically to mental illness. Given that a large number of web-based resources are designed to provide services specifically for people with mental health problems, accessibility of the information itself is paramount to ensure that regardless of disability or impairment, websites should strive for inclusiveness.

To clarify, the Web Content Accessibility Guidelines 2.0, which were developed to help designers create content that is accessible regardless of disability, have developed guidelines under 4 main principles: perceivable; understandable; operable and robust.

1. Perceivable - Information and user interface components must be presentable to users in ways they can perceive and not be invisible to all senses

2. Operable - User interface components and navigation must be operable and not require interaction that a user cannot perform

3. Understandable - Information and the operation of user interface must be understandable.

4. Robust - Content must be robust enough that it can be interpreted reliably by a wide variety of user agents, including assistive technologies. (WCAG 2.0, 2012).

Guidelines to help web designers create content that is accessible to people with disabilities or impairments are produced by the W3C Web Accessibility Initiative 
group. The website also provides extensive information on how people with different disabilities are able to use the Web. Disabilities or impairments are categorized as follows: Auditory; Cognitive and neurological; Physical; Speech and Visual (W3C, WAI, 2012). Within the category 'Cognitive and neurological' are a range of disabilities that do also include 'Mental health disabilities', which cover mental illnesses from psychosis through to anxiety and depression. Accessibility problems with this user group are cited as:

"Difficulty focusing on information, processing information, or understanding it. In particular medication for these disorders may have side effects including blurred vision, hand tremors, and other impairment" (W3C/WAI, 2012).

\subsection{W3C/WAI Guidelines for Cognitive and Neurological Impairments}

The W3C/WAI does provide general guidelines for designing content that is accessible for cognitive and neurological impairments:

- Clearly structured content that facilitates overview and orientation

- Consistent labelling of forms, buttons, and other content parts

- Predictable link targets, functionality, and overall behavior

- Different ways of navigating websites, such as through a hierarchical menu or search option

- Options to suppress blinking, flickering, flashing, or otherwise distracting content

- Simpler text that is supplemented by images, graphs, and other illustrations (W3C/WAI, 2012).

Whilst there are guidelines in place that cover the general area of cognitive impairments, the premise of this paper is to look design elements that specifically cause problems for people with mental illness, but in particular, anxiety and depression. We are interested to find out whether there are general themes with the problems our targeted user group might experience and the degree of anxiety experienced. This could then help web designers to better understand the importance of accessibility for this user group and the main issues to address.

\section{Understanding Accessibility Issues for People with Anxiety and Depression}

It is important for our research to gain users' perspective of accessibility issues for this user group. To this extent, we wanted to carry out user centered research and talk to people who experience anxiety and depression. The aim of the research was to gain a better understanding of the accessibility issues this user group experience. 


\subsection{Method: Focus Group}

We considered an appropriate tool for user centered research was a focus group, made up of people who have had a diagnosis of anxiety and/or depression. Two focus groups were held, each with 10 people plus a facilitator. Participants were asked to complete two tasks. The first task was locating information that advised on their condition from two websites of their choice. The rationale for this task was based upon the extent to which people use the Web to find information about mental health; 1 in 5 people (Powell et al, 2007). The second task was to find a self-help book relating to their condition, using an online shop of their choice. The rationale for this task relates to the extent to which people seek self-help books (Harwood \& L'Abate, 2010). Participants were asked to write down the problems they encountered and to rate the level of anxiety that each problem caused, from 1-3, with 1 being low anxiety, 2 being moderate anxiety and 3 being assigned as a high level of anxiety.

\subsection{Results}

The participants identified a range of issues that caused difficulties when carrying out the tasks.

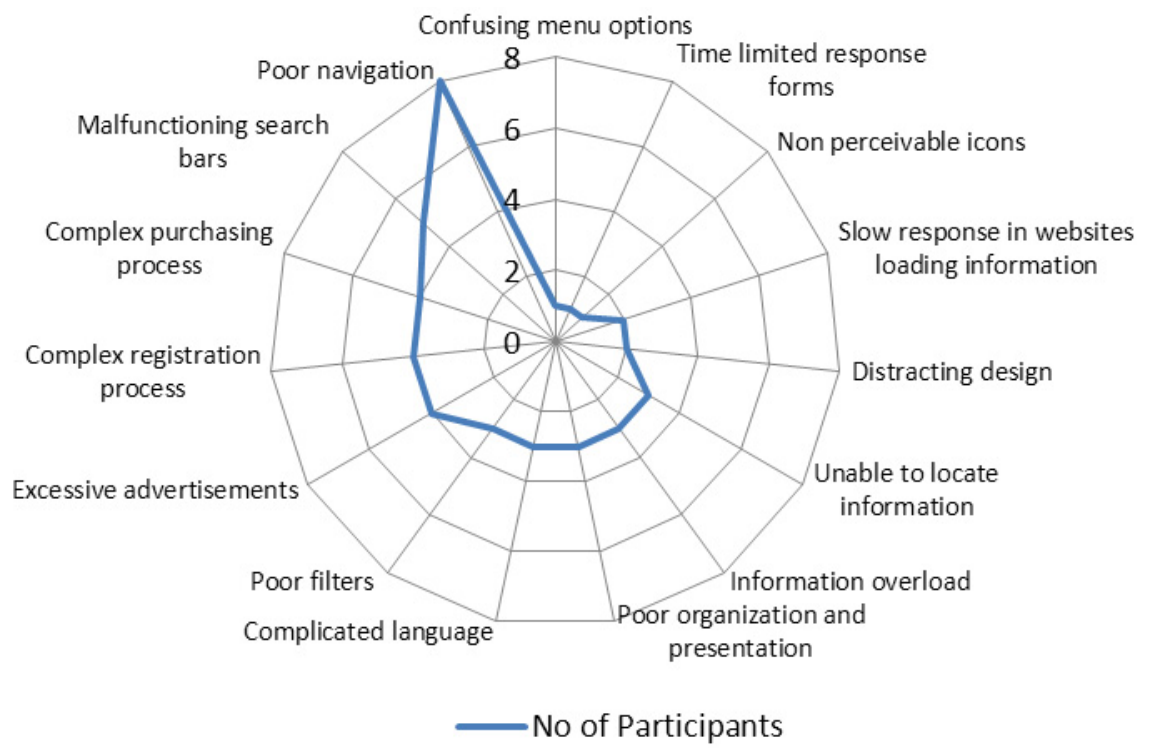

Fig. 1. Design Elements Affecting Accessibility for People with Anxiety and Depression

Furthermore, we were able to see the degree of anxiety which some design elements caused. Figure 1 shows the identified issues, along with the predominance of each issue. Poor navigation is shown to be the most commonly reported issue 
amongst the 20 participants, with 8 identifying it as being a significant problem. Other notable issues were: malfunctioning search bars; confusing menu options; complex purchasing process and registration process as well as excessive advertisements.

Whilst we wished to identify common accessibility problems with this user group, we were also interested as to what extent these problems caused anxiety. In figure 2 , we can see that the issues that tended to cause the most anxiety related to problems with: locating information; poor navigation; malfunctioning search bars and a complex purchasing process. These results correlate with the number of participants that identified these issues as being problematic, as shown in figure 1 .

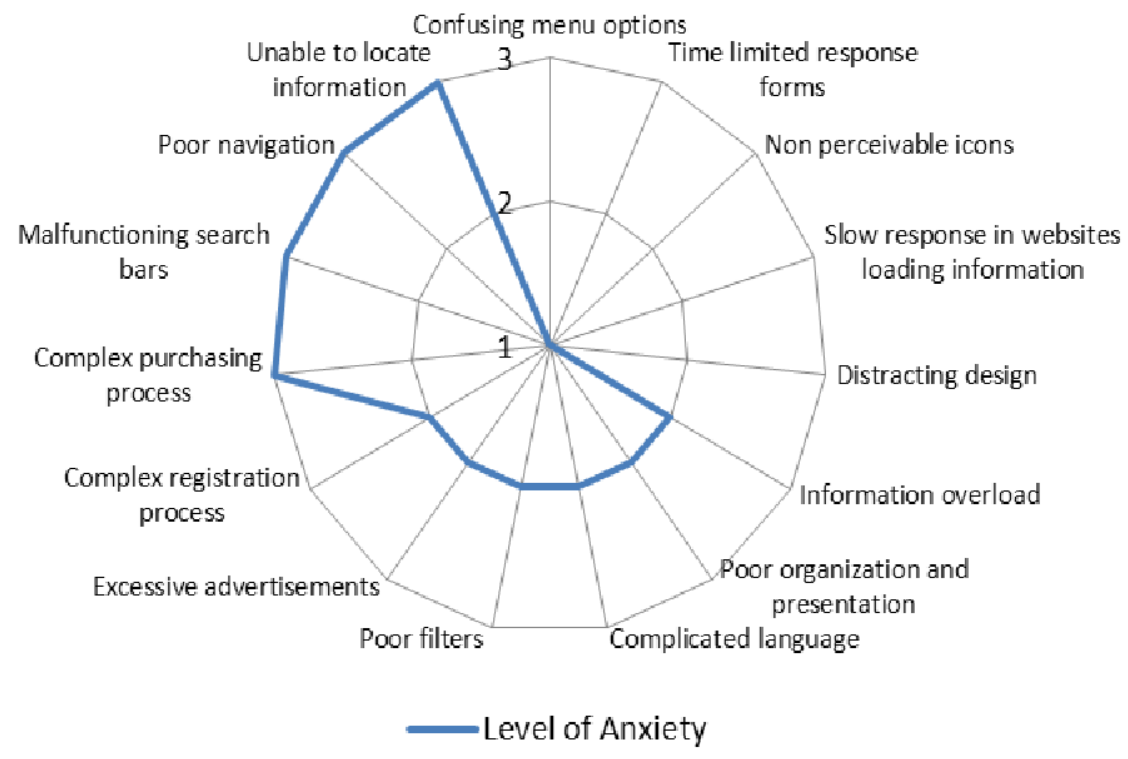

Fig. 2. Design Elements Increasing Anxiety for People with Anxiety and Depression

\section{Discussion}

Whilst the results from this research indicate common accessibility problems for this user group, we were interested in whether there were any identified common themes. We were able to establish three common themes from the 14 issues raised. These were notably issues with the presentation of information, understanding of information and searching of information. Table 1 shows how the issues were categorized into themes, with the associated number of participants included. 
Table 1. Categorizing Design Elements Causing Accessibility Issues

\begin{tabular}{|c|c|c|c|c|c|c|c|}
\hline $\begin{array}{l}\text { Presenting } \\
\text { Information }\end{array}$ & & $\begin{array}{l}\text { Understanding } \\
\text { Information }\end{array}$ & & $\begin{array}{l}\text { Searching } \\
\text { Information }\end{array}$ & & Other & \\
\hline Distracting design & 2 & $\begin{array}{l}\text { Confusing menu } \\
\text { options }\end{array}$ & 1 & Poor navigation & 8 & $\begin{array}{l}\text { Time limited response } \\
\text { forms }\end{array}$ & 1 \\
\hline Information overload & 3 & $\begin{array}{l}\text { Non perceivable } \\
\text { icons }\end{array}$ & 1 & $\begin{array}{l}\text { Unable to locate } \\
\text { information }\end{array}$ & 3 & $\begin{array}{l}\text { Slow response in } \\
\text { websites loading } \\
\text { information }\end{array}$ & 2 \\
\hline $\begin{array}{l}\text { Poor organization } \\
\text { and presentation }\end{array}$ & 3 & $\begin{array}{l}\text { Complicated } \\
\text { language }\end{array}$ & 3 & Poor filters & 3 & & \\
\hline $\begin{array}{l}\text { Excessive } \\
\text { advertisements }\end{array}$ & 4 & $\begin{array}{l}\text { Complex purchasing } \\
\text { process }\end{array}$ & 4 & $\begin{array}{l}\text { Malfunctioning } \\
\text { search bars }\end{array}$ & 5 & & \\
\hline
\end{tabular}

We can then see in figure 3 , a comparison of the identified themes. Issues that relate to 'searching for information' were most prevalent.

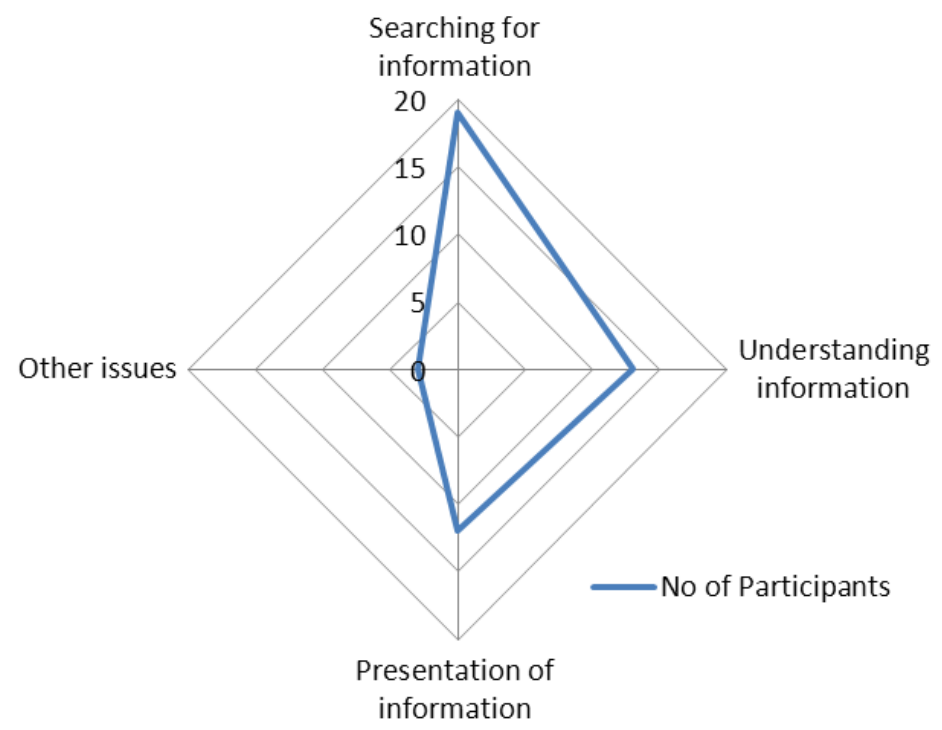

Fig. 3. Categorizing Design Elements Causing Accessibility Issues

Certainly the issue with understanding information correlates with the W3C/WAI guidelines that state people with cognitive impairments experience: "Difficulty focusing on information, processing information, or understanding it" (W3C/WAI, 2012). Furthermore, the guidelines for web designers provided by W3C/WAI also correlate to the general themes identified in this research, as seen in table 2. 
Table 2. Correlating themes with W3C/WAI Guidelines

\begin{tabular}{|l|l|}
\hline W3C/WAI Guideline & Identified Themes from the Research \\
\hline $\begin{array}{l}\text { Clearly structured content that } \\
\text { facilitates overview and orientation }\end{array}$ & Presentation /Searching \\
\hline Consistent labelling of forms etc & Presentation \\
\hline Predictable link targets & Understanding / Searching \\
\hline Different ways of navigating sites & Searching \\
\hline Options to supress distracting content & Presentation \\
\hline Simpler text & Understanding \\
\hline
\end{tabular}

Perhaps the most notable finding from this research is the theme of accessibility problems that cause the most anxiety for this user group, that being searching for information. In figure 2.2, we see that out of the 4 issues that cause the greatest anxiety, 3 of these relate to problems relating to searching for information. We know from the literature featured earlier in the paper that people with anxiety and depression can experience difficulties with cognitive functioning, relating to learning, memory and attention (Papazacharias \& Nardini 2012; Gualtieri \& Morgan 2008; Porter at Al, 2003).

Recommendations to Web designers, particularly when designing web based resources in mental health are categorized under the accessibility themes:

- Searching for Information: Provide intuitive navigation and ensure filters and search functions work properly.

- Presentation of information: Ensure information is organized well and avoid distracting design.

- Understanding of information: Avoid complicated language and ensure menu options and links are easy to understand.

Further to these recommendations is to advise Web designers to carry out user centred evaluation of their Web sites. These can be as simple as cognitive walkthroughs using predominant tasks, as well as more involved user testing.

This research should be considered more as an exploratory study, given the small number of participants, and therefore the results should be viewed as indicative and also as a prelude to further research into evaluating and improving accessibility to Web based mental health resources.

\section{References}

1. Airaksinen, E., Larsson, M., Forsell, Y.: Neuropsychological functions in anxiety disorders in population-based samples: evidence of episodic memory dysfunction. Journal of Psychiatric Research 39, 207-214 (2005)

2. Airaksinen, E., Larsson, M., Forsell, Y.: Low episodic memory performance as a premorbid marker of depression: evidence from a 3-year follow-up. Acta Psychiatrica Scandinavica 115(6), 458-465 (2007) 
3. Campbell, S., Marriott, M., Nahmias, C., MacQueen, G.M.: Lower hippocampal volume in patients suffering from depression: a meta-analysis. Am. J. Psychiatry 161, 598-607 (2004)

4. Doherty, G., Coyle, D., Matthews, M.: Design and evaluation guidelines for mental health technologies. Interacting with Computers 22(4), 243-252 (2010)

5. Fox, S.: Health information online. The Pew Internet \& American Life Project (2005), http: / / www.pewinternet.org/PPF/r/156/report_display.asp (retrieved)

6. Frodl, T., Meisenzahl, E.M., Zetzsche, T., et al.: Hippocampal changes in patients with a first episode of major depression. Am. J. Psychiatry 159, 1112-1118 (2002)

7. Good, A., Sambhantham, A., Panjganj, V.: Looking back at facebook content and the positive impact upon wellbeing: Exploring reminiscing as a tool for self soothing. In: Ozok, A.A., Zaphiris, P. (eds.) OCSC 2013. LNCS, vol. 8029, pp. 278-286. Springer, Heidelberg (2013)

8. Gualtieri, T., Morgan, D.: The frequency of cognitive impairment in patients with anxiety, depression, and bipolar disorder: an unaccounted source of variance in clinical trials. The Journal of Clinical Psychiatry, 69-712 (2008)

9. National Institute of Mental Health, Anxiety Disorders (2012)

10. http://www.nimh.nih.gov/statistics/1anyanx_adult.shtml

11. Office for National Statistics. Measuring National Well-being-Health 2013. Br. J. Psychiatry 189, 273-277 (2013), http: / / www. ons.gov.uk/ons / dcp171766_310300.pdf

12. Papazacharias, A., Nardini, M.: The Relationship Between Depression and Cognitive Deficits. Psychiatria Danubina 24(suppl. 1), 179-182 (2012)

13. Powell, J., Clarke, A.: Internet Information Seeking in Mental Health: Population Survey. In: BRJ. Psychiatry (2007)

14. Ritterband, L.A., Gonder Frederick, D.J., Cox, A.D., et al.: Internet interventions in review, in use, and into the future. Professional Psychology Research and Practice 34, 527-534 (2003)

15. Van De Belt, T.H., Engeleni, L., Berbent, S.A.A., Schoonhoven, L.: Definition of Health 2.0 and Medicine 2.0: A Systematic Review. Journal of Medical Internet Research 12(2) (2010)

16. W3C/WAI, How People with Disabilities Use the Web. W3C (2012), http: / / www .w3 . org/WAI/intro/people-use-web/diversity\#cognitive 